\title{
Anatomical and Morphological Study of Nutrient Foramen in Leg Bones
}

\author{
Donapudi Anusha', D. Madhavi ${ }^{2}$, Srinidhi Kondepudi ${ }^{3}$ \\ ${ }^{1}$ Assistant Professor, Dr. Pinnamaneni Siddhardha institute of medical sciences and research foundation, Chinnaoutpalli, ${ }^{2}$ Associate Professor, Guntur \\ Medical College, Guntur, A.P. ${ }^{3}$ House surgeon NRI Medical College, Chinnakakani, Guntur, A.P.
}

\section{Abstract}

Introduction: Knowledge of position of nutrient foramina of long bones can be useful in certain surgical procedures. Bone ossification, growth and healing depend on its vascularity. Nutrient artery is the main source of blood supply of bone along with periosteal arteries. The topographical knowledge of these foramina is useful in certain operative procedures, in orthopedics as well as in plastic and reconstructive surgeries. AIM: The present study aims to determine the number and position of nutrient foramen of tibia and fibula and to observe direction and obliquity of nutrient foramina. Subjects and Methods: 100 adult dry bones including 50 tibia and 50 fibula were studied. Nutrient foramina were identified with naked eyes. The obliquity was determined with hypodermic needle. The nutrient foramina location was determined by dividing total bone into segments, the locations were validated by calculating foraminal index. Results: It has been observed that $98 \%$ (49) tibia has single nutrient foramina, double nutrient foramiana present in $2 \%$ of tibia. Most of the nutrient foramina in tibia are present in upper third i.e 65\% (33). Foramina index of tibia is 45.05 with standard deviation of 8.29.In fibula single foramen was observed in 46 (92\%) and double foramina 2 (4) and there is no nutrient foramen in 2 (4). In 2 fibulae having double nutrient foramen, proximal foramen was directed downward and distal foramen was directed upwards. In 50\% (25) nutrient foramina is present in posterior surface, most of nutrient are in middle third 48 (96\%).mean foraminal index of fibula is 45.05 with standard deviation of 8.29 . Conclusion: Our study has attempted to put together findings from different studies regarding the number and position and obliquity of nutrient foramina of leg bones. The present study will be useful for orthopedic surgeons during procedures like bone grafting and more recently microsurgical vascularised bone transplantation and new graduates to understand the importance of nutrient foramina of long bones.

Keywords: Nutrient artery Nutrient foramen, foraminal index, tibia, fibula, reconstructive surgeries.

Corresponding Author: Dr. D. Madhavi, Associate Professor, Guntur Medical College, Guntur. A.P.

Received: June 2019

Accepted: June 2019

\section{Introduction}

Nutrient artery is the chief artery supplying the long bone along with periosteal arteries. They usually take origin from regional artery of that region. The nutrient artery enters shaft of the long bones, through a foramen termed "nutrient foramen". Nutrient foramen is an opening in the shaft of long bone which conducts the nutrient arteries and the peripheral nerves into the medullary cavity of a long bone. One or two main diaphyseal nutrient arteries enter the shaft obliquely through one or two nutrient foramina leading to nutrient canals. ${ }^{[1]}$ In case where the nutrient foramen is absent it is likely that periosteal vessels as entirely responsible for blood supply of bone. ${ }^{[10]}$ The nutrient foramen may be area of potential weakness in some patients. ${ }^{[8]}$ The direction of nutrient foramen of all bones is away from growing end. Longitudinal stress fractures may be associated with nutrient foremen and are commonly seen in tibia,but occasionally in the femur, fibula and patella. ${ }^{[9]}$ Variations in direction of nutrient foramina have been observed in many tetrapod's and there is some similarity in the nutrient foraminal pattern in mammals and birds. ${ }^{[2]}$ In this study the localization and number of the nutrient foramina on the lower limb long bones have been investigated and the relevant literature reviewed and compared.

\section{Subjects and Methods}

The present study was conducted in 100 cleaned and dried human adult tibia and fibula. Hepburn Osteometric board, sliding calipers, hand lens, stiff wire and 21-gauge needle were used during study. They were obtained from the Department of Anatomy Dr.pinnamineni Siddhartha institute of medical sciences and research foundation.

Bones without any abnormalities were selected for the present study. Parameters like age \& sex were not considered. Each of tibia and fibula was observed by using a magnifying lens for nutrient foramen on the shaft. Nutrient foramen was identified by its specific features like elevated margins and distinct groove proximal to it. Only welldefined foramina on the diaphysis were accepted. Foramina at the ends of the bone are ignored. 


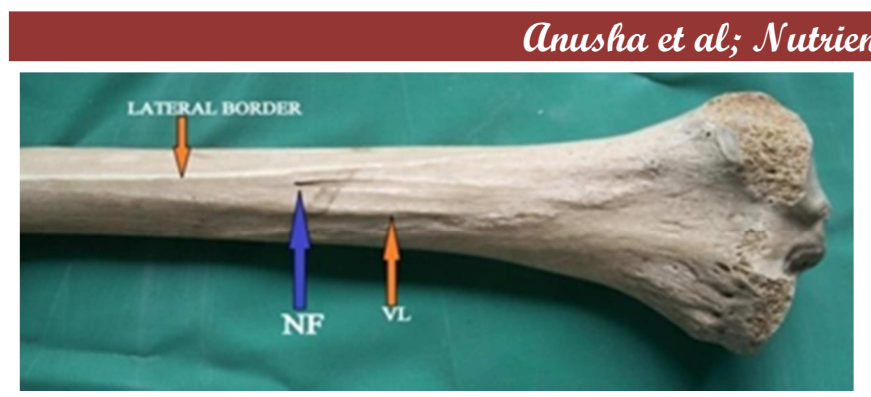

Tibia showing single nutrient foramen lateral to ventral line on posterior surface of the shaft, directed downwards.

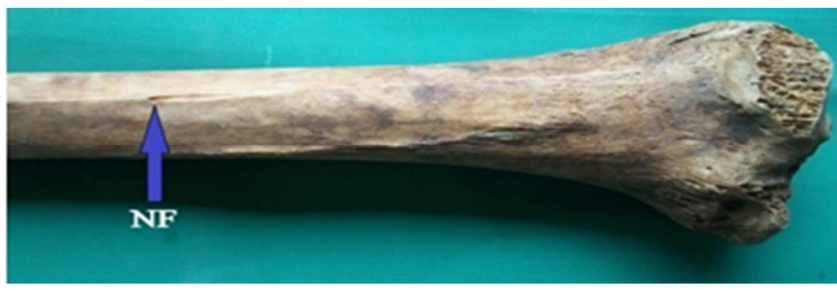

Tibia showing single nutrient foramen on the lateral boarder of shaft, directed downwards.
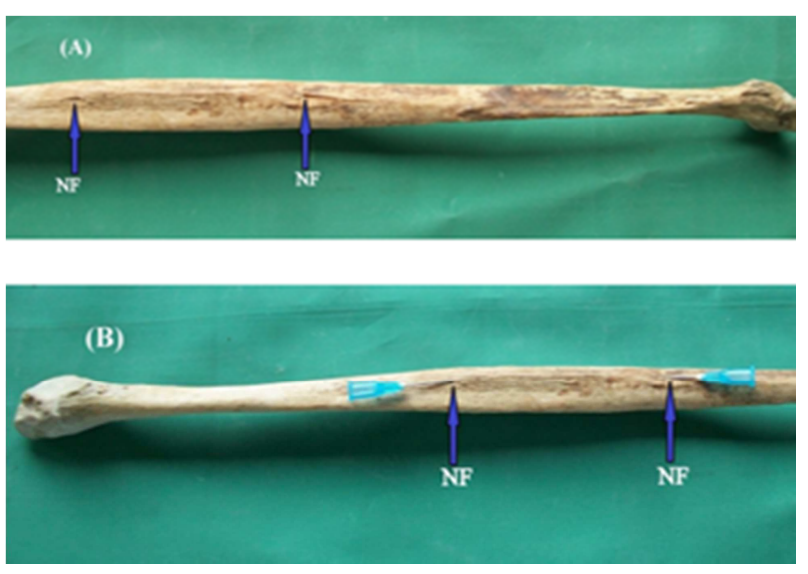

aramen in Leg Banes

the shaft.

b) The proximal foramen is directed downwards and distal foramen upwards.

\section{Results \& Discussion}

Total Length of Bone:

Tibia: The distance between the proximal margin of the medial condyle and the tip of the medial malleolus.

Fibula: The distance between the apex of the head of the fibula and the tip of the lateral malleolus

\section{Distance of nutrient foramina from upper end of bone:}

It is measured from the most proximal end of the bone to the nutrient foramen by sliding calipers.

\section{Foramina index:}

The position of all nutrient foramina was determined by calculating the foraminal index $(\mathrm{FI})$ using the formula:

$$
\mathrm{FI}=(\mathrm{DNF} / \mathrm{TL}) \times 100
$$

Where $\mathrm{DNF}=$ the distance from the proximal end of the bone to the nutrient foramen; $\mathrm{TL}=$ Total bone length; $\mathrm{FI}=$ foraminal index.

Comparison of various studies of tibia with present study In all the studies [Table 3] more than $96 \%$ of tibia had single nutrient foramen while remaining had double foramen. In the present study we noted maximum tibia had single foramen $2 \%$ has double nutrient foramen which have been mentioned by previous authors (Collipal E et al.,2007; Longia Gs et al 1980; 1987;sendemire et al 1991;gumusburanE et al.,1994; Kizilkanat E et al., 2007 ; )Presence of double NF in present study is in concurrence with all above authors except gumusburun et al.,(1994); where he got $11 \%$. He also reported $2.8 \%$ having $3 \mathrm{NF}$, $0.9 \%$ with no NF. Swapna et al study says that there are 3.8 $\%$ of 3 nutrient foramen.

a) Fibula showing nutrient foramen on posterior surface of

\begin{tabular}{|c|c|c|c|c|c|c|}
\hline \multirow[t]{2}{*}{ Studies (tibia) } & \multirow[t]{2}{*}{ Mean length (mm) } & \multirow[t]{2}{*}{ Position of maximum nutrient foramen } & \multicolumn{4}{|c|}{$\%$ of nutrient foramen } \\
\hline & & & 1 & 2 & 3 & Absent \\
\hline Kazilkanth et al $^{[3]}$ & 358 & middle & 98 & 2 & NA & NA \\
\hline Udhya Et al $^{[7]}$ & 355.5 & upper & 96.3 & 3.7 & NA & NA \\
\hline Sharma et a ${ }^{[6]}$ & NA & NA & 96 & 4 & NA & NA \\
\hline Mazengenya et al ${ }^{[5]}$ & 384.4 & upper & 99.4 & 0.6 & NA & NA \\
\hline Mazengenya et al ${ }^{[5]}$ & 371.2 & upper & 98.3 & 1.7 & NA & NA \\
\hline Swapna A et al ${ }^{[1]]}$ & 361.9 & upper & 94.3 & 1.9 & 3.8 & NA \\
\hline Present study & 375.5 & upper & 98 & 2 & NA & NA \\
\hline
\end{tabular}

Present study is cognate with other researchers for location and location of maximum foramina except Kazilkant et al had reported maximum foramens were on middle third of tibia.
The mean length of tibia varied between 355.5 and 375.5 $\mathrm{mm}$ in all studies. The mean length of tibia is similar to previous studies (Collipol et al endemir et al, 1991; Gumusburun et al 1994 and Kizilkanth et al, 2007)

\begin{tabular}{|c|c|c|c|c|c|}
\hline Studies (fibula) & Mean length $(\mathrm{mm})$ & $\%$ of nutrient foramina & & & \\
\hline & & 1 & 2 & 3 & Absent \\
\hline Kazilkant et al ${ }^{[3]}$ & 340.2 & 93.1 & 5.5 & NA & 1.4 \\
\hline Sharma et al ${ }^{[6]}$ & NA & 92 & NA & NA & 8 \\
\hline $\begin{array}{l}\text { Mazengenya et al black } \\
\text { Africans }{ }^{[5]}\end{array}$ & 367.6 & 87 & 5 & 1 & 7 \\
\hline $\begin{array}{l}\text { Mazenenya et al white } \\
\text { Africans }{ }^{[5]}\end{array}$ & 360.7 & 86.1 & 8.9 & NA & 5 \\
\hline Swapan et al ${ }^{[11]}$ & 353.5 & 63.5 & 7.7 & 1.9 & 5 \\
\hline Present study & 364.5 & 92 & 4 & NA & $4 \%$ \\
\hline
\end{tabular}




\begin{tabular}{|l|l|l|}
\hline Number of Nutrient Foramen & Number of Bones & Percentage \\
\hline Single & 49 & $98 \%$ \\
\hline Double & 1 & $2 \%$ \\
\hline
\end{tabular}

\section{Percentage and Distribution of Nutrient Foramen in Tibia}

Tibial mean FI was seen as 32.93 ranging betwwn 27.8 to 40 and located mainly in proximal third $(65 \%)$ and $(35 \%)$ in middle third.

Bhatnagar et al and Pereira et al reported tibial mean FI as $(34.49 \%)$ and $(32.7 \%)$ respectively which differed statistically $(\mathrm{p}<0.05)$ but mean FI $(31.2 \%)$ by Kizilkanat et al, was differed insignificantly from studied specimens.

Comparison of various studies if fibula with present study The mean length of fibula is between $340-376 \mathrm{~mm}$ in present study which is in concurrence with previous studies (Sendemir et al, 1991; Gumusburan E et al, 1994; KIzilkanath et al, 2007)

The FI was observed to range between 31.6 to 69.1 .The result is almost similar to the studies reported by Campos et al, (1987); Sendemir et al.,(1991) Gumusburun et al, (1994), Vijayalakshmi SB. Et al, (2016)

In our study single NF were present mostly in middle third of the shaft which is similar to other authors as shown in above table such as Mazengenya et al, Swapna et al, Collipol et al, absence of nutrient foramina in fibula were reported by previous authors (Sendemir et al, 1991; Gumusburun et al, 1994; Kizilkanat et al, 2007; Mysorekar VR, 1967 and MC KeeEt. Al 1984).

In the present study absence of NF was seen in $4 \%$. In 2 fibulae having double nutrient foramen, the proximal foramen was directed downwards and distal foramen was directed upwards.

\section{Percentage and Distribution of Nutrient Foramen in $\underline{\text { Fibula }}$}

\begin{tabular}{|l|l|l|}
\hline Number of NF & Number of bones & Percentage \\
\hline None & 2 & $4 \%$ \\
\hline Single & 46 & $92 \%$ \\
\hline Double & 2 & $4 \%$ \\
\hline
\end{tabular}

Majority of NF in the present study (96\%) are located in middle 1/3 of bone. They are alike with the (Longia GS Et al 1980; Campos F et al, 1987; and with. ${ }^{[5,11]}$ In the present study $2 \%$ of $\mathrm{NF}$ are located in upper third and $2 \%$ are present in lower third.

\section{Conclusion}

Our study has attempted to put together findings from different studies regarding the number and position and obliquity of nutrient foramina of leg bones .The present study will be useful for orthopedic surgeons during procedures like bone grafting and more recently microsurgical vascularised bone transplantation and new graduates to understand the importance of nutrient foramina of long bones.

\section{Acknowledgement}

I would like to express my sincere gratitude to Dr.Madhavi Associate Professor Dept of Anatomy, for continuous Support, for her patience, motivation and guidance in all the time of research .I would like to thank all technical and nonteaching staff of department of anatomy for their constant help and cooperation.

\section{References}

1. H. Grey, P.L. Williams, L.H. Bannister, M.M. Berry, P.Collins, M. Dyson, J.E. Dussek, M.W.J. Ferguson etal.1995. Gray's Anatomy: 38 edition. London,Churchill Livingstone. 1995:1417.

2. Mysorekar VR. Diphysial nutrient foramina in humanlong bones. J Anat. 1967;101(4): 813-822.

3. Kizilkanat E, Boyan N, Ozsahin ET, Soames R, OguzO. Location, number and clinical significance of nutrient foramina in human long bones. Ann. Anat.,2007;189:87-95.

4. Longia GS, Ajmani ML, Saxena SK, Thomas RJ, Studyof diaphyseal nutrient foramina in human long bones, ActaAnat (Basel), 1980;107(4):399-406.

5. Mazengenya P. and Fasemore M.D., Morphometricstudies of the nutrient foramen in lower limb long bones of adult black and white South Africans Eur.J. Anat. 2015;19(2):155-163.

6. Sharma M, Prashar R, Sharma T, Wadhwa A, Kaur J.Morphological variations of nutrient foramina in lower limb long bones. Int J Med and Dent Sci2015;4(2):802-808

7. Udhaya K., Devi K.V., Sridhar J., Analysis Of NutrientForamen Of Tibia-South Indian Population Study Int J Cur Res Rev, April 2013;05(08):91-98.

8. Saad J., Zrig A. Marrakchi F, Harbi F., Alghamdi S.Longitudinal Stress Fracture: Patterns Of Edema And The Importance Of The Nutrient Foramen In MRIEvaluation. European society of radiology 2015;1-17.

9. Craig, J.G., Widman, D., van Holsbeeck, M., Longitudinalstress fracture: patterns of edema and theimportance of the nutrient foramen. Skeletal Radiol.2003;32:22-27.

10. Mc.Gregor, Du Plessis. 1969. A Synopsis of Surgical Anatomy.

11. Swapna A.Ambekar,Shivaji B.Sukre.Diaphysial Nutrient foramen of lower limb long bones :Variations and importance.INT j Anat Res 2016;4(3):2684-2688.

Copyright: () the author(s), publisher. Academia Anatomica International is an Official Publication of "Society for Health Care \& Research Development". It is an open-access article distributed under the terms of the Creative Commons Attribution Non-Commercial License, which permits unrestricted non-commercial use, distribution, and reproduction in any medium, provided the original work is properly cited.

How to cite this article: Anusha D, Madhavi D, Kondepudi.S. Anatomical and Morphological Study of Nutrient Foramen in Leg Bones. Acad. Anat. Int. 2019;5(2):8-10.

DOI: dx.doi.org/10.21276/aanat.2019.5.2.3

Source of Support: Nil, Conflict of Interest: None declared. 